\title{
Staged Surgery for Giant Fecaloma Complicating Idiopathic Megacolon
}

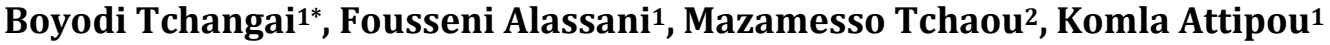 \\ ${ }^{1}$ Department of Surgery, Sylvanus Olympio Teaching Hospital, Lome, Togo \\ ${ }^{2}$ Department of Radiology, Sylvanus Olympio Teaching Hospital, Lome, Togo \\ Email: ^botchangai@yahoo.fr
}

How to cite this paper: Tchangai, B., Alassani, F., Tchaou, M. and Attipou, K. (2016) Staged Surgery for Giant Fecaloma Complicating Idiopathic Megacolon. Open Journal of Gastroenterology, 6, 418-422. http://dx.doi.org/10.4236/ojgas.2016.612044

Received: November 7, 2016

Accepted: December 18, 2016

Published: December 21, 2016

Copyright $\odot 2016$ by authors and Scientific Research Publishing Inc. This work is licensed under the Creative Commons Attribution International License (CC BY 4.0).

http://creativecommons.org/licenses/by/4.0/

\section{(c) (i) Open Access}

\begin{abstract}
Fecalomas that need surgical management are uncommon. We report a rare case of giant fecaloma in a 22 years old female, with a history of constipation since childhood and an abdominal mass. Abdomen CT scan revealed a giant fecaloma filling sigmoid lumen without signs of ischemia or either complications. Laparotomy and fecaloma extraction trough colotomy was undertaken after failure of conservative measures and endoscopic removal attempt. Hirschsprung disease having been ruled out, sigmoidectomy was performed for idiopathic megacolon. Post operative course was uneventful with good functional outcomes.
\end{abstract}

\section{Keywords}

Giant Fecaloma, Idiopathic Megacolon, Sigmoidectomy

\section{Introduction}

Fecaloma is an accumulation of hardened fecal concretions usually located in the colon or rectum. It is a common problem among the elderly and neuropsychiatric patient which however can lead to serious complications such as obstruction and perforation [1]. As they are related to transit constipation or difficulty in rectal emptying, fecalomas can be managed with conservative measures including dietetic care, laxatives, digital or endoscopic extraction. Conservative management has been exceptionally unsuccessful in some cases of giant fecalomas presenting as an abdominal mass [2]. We report a rare case of giant fecaloma in a young female, requiring investigations and a two stage surgical management. 


\section{Case Description}

A 22 years old female was admitted for an abdominal mass of six months duration with severe constipation. Medical history consisted of transit disorders since childhood and the need to frequently perform a rectal enema to have stools. These disorders were well tolerated and therefore did not lead to medical intervention. Constipation worsened 6 months before admission with 1 liquid stool per week and a sensation of incomplete emptying. There were no other pathological conditions, no psychiatric disorders, no current medication and no drug addiction. Physical examination showed a good general condition, with a firm, mobile abdominal mass in the hypo gastric area. There were no pathological findings upon rectal examination. Ultrasonography showed heterogeneous highly echotic mass suggestive of fecal impaction. Abdominal CT revealed a giant fecaloma with sigmoid distension without signs of ischemia (Figure 1). Conservative treatment consisting of dietetic care, mineral laxatives and enemas was undertaken for 5 days without any improvement.

The fecaloma was not palpable on rectal examination so digital disimpaction was not considered as part of the treatment. Endoscopic attempt to remove the fecaloma was ineffective. Failure of conservative management and worsening of initial symptoms led to a surgical option. Exploration via middle line laparotomy revealed a distended sigmoid colon containing a fixed hard mass up to the recto sigmoid junction (Figure 2). A sigmoid colotomy allowed to extract a giant 2.6 $\mathrm{kg}$ fecaloma. The surgical procedure ended by lateral colostomy with colonic and rectal biopsies. Post operative period was uneventful with regular emission of stools through the colostomy. Barium enema performed one month after surgery showed a megadolicho-sigmoid. Histological studies confirmed the presence of ganglion nerve cells in the submucosal and myenteric plexus in the rectal specimen, ruling out Hirschsprung disease. The colonic specimen showed hyperplasia of the muscularis mucosae and non specific inflammatory infiltration. Laboratories studies excluded diabetes, hypothyroidism and hypokalemia. The patient was diagnosed with idiopathic mega-sigmoid and benefitted from sigmoid resection with colorectal anastomosis. Post operative course was simple. She had 3 bowel movements per week, of firm consistency, after 3 years followup.

\section{Discussion}

Fecaloma is a common manifestation of constipation, which, exceptionally, presents as an abdominal mass related to a giant fecal impaction [2] [3]. In these cases, it is a sign of severe and chronic bowel dysfunction. Plain abdominal radiography is usually suggestive of fecal impaction. Diagnosis can be established with abdominal ultrasound, though this may be difficult with gaseous abdominal distension [4]. Abdomen CT scan is the most effective diagnostic tool which can also show compressive complications such as ischemia, obstructive uropathy [5], 


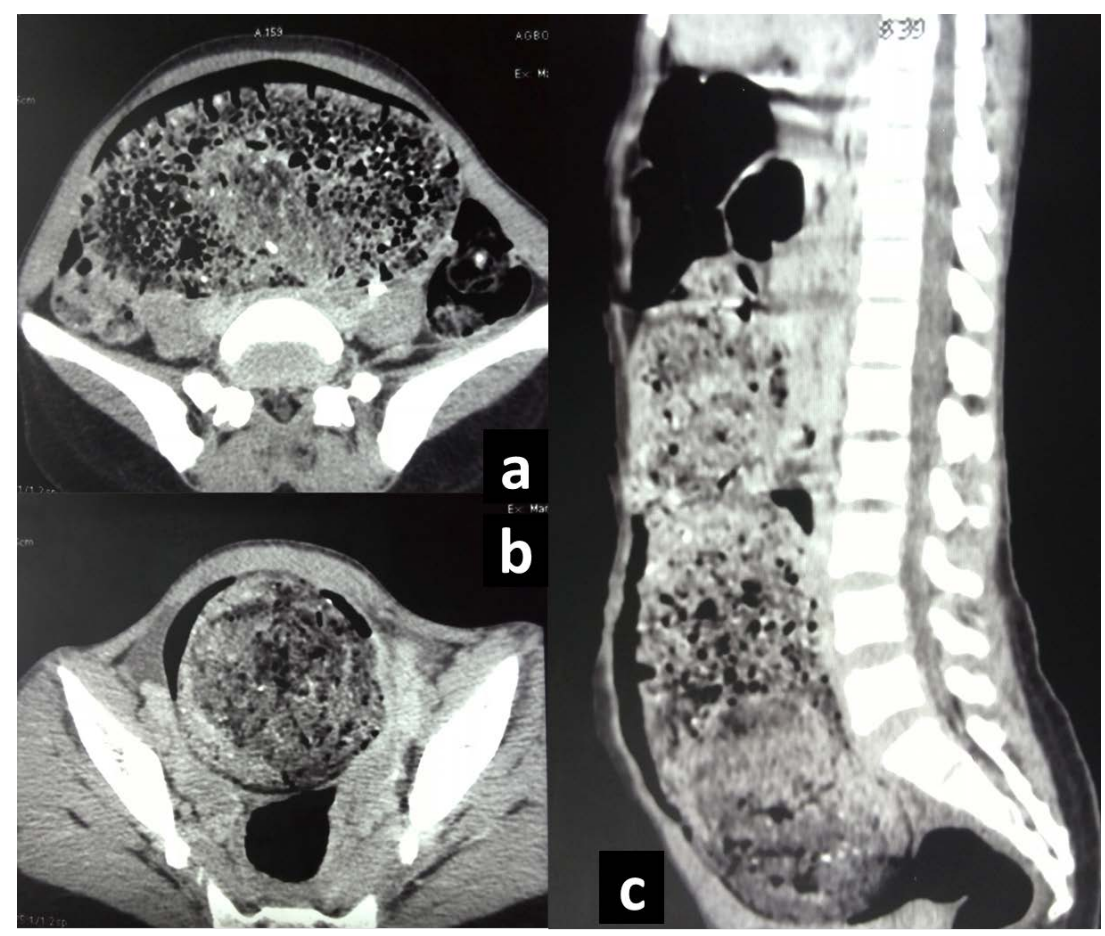

Figure 1. Injected abdomen CT revealing a giant fecaloma filling sigmoid lumen top to recto-sigmoid junction.

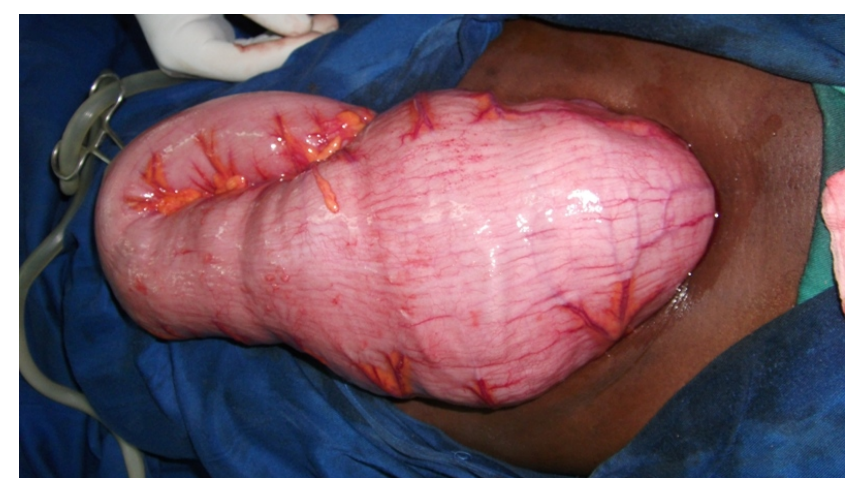

Figure 2. Operative view showing dilatation of sigmoid colon containing a giant fecaloma.

deep vein thrombosis [6], and colonic dilatation [7].

The disease evolution, together with physical examination can provide clues that avoid exhaustive etiological investigations. These include spinal cord disorders [6], history of anorectal surgery [8]. Giant fecaloma occurring in an otherwise healthy young adult is rare. Regarding lifelong symptoms of constipation, especially in children and young adults, Hirschprung's disease should be systematically investigated. In this report, disease history, colonic dilatation and absence of histological abnormality, were in favor of idiopathic megacolon. Although not congenital, the disease may present as chronic constipation evolving from childhood [2] [3].

Conservative treatment of giant fecal impaction can be effective [6], however 
colon perforation has been described as a consequence of delayed surgical treatment [5]. Poor outcomes of subsequent stercoral peritonitis should be considered in the treatment indications. At the moment of surgery, bowel resection is almost systematic [3] [5] [7] [8]. The extent of resection depends on the etiology and the presence of complications. When associated with idiopathic sigmoid megacolon, giant fecalomas could be treated by sigmoidectomy with primary colorectal anastomosis [2] [3] or Hartman procedure considering the risk of anastomotic leakage. Giant fecaloma extraction through colon incision as we did has not been described in the literature to our knowledge. In this indication due care must be taken in colon vitality evaluation and surgical field protection. The extent of intestinal resection could then be decided in an elective procedure in order to achieve optimal functional outcome.

\section{Conclusion}

Giant fecaloma should be considered in the diagnosis of any abdominal mass with long term constipation. Even though first line treatment is conservative, surgery should be considered before the onset of complications.

\section{Consent}

Written informed consent was obtained from the patient for publication of this case report and accompanying images. A copy of the written consent is available for review by the Editor-in-Chief of this journal on request

\section{Conflicts of Interests}

The authors declare that there is no conflict of interest regarding the publication of this paper.

\section{References}

[1] Hussain, Z.H., Whitehead, D.A. and Lacy, B.E. (2014) Fecal Impaction. Current Gastroenterology Reports, 16, 404. https://doi.org/10.1007/s11894-014-0404-2

[2] Rajagoppal, A. and Martin, J. (2002) Giant Fecaloma with Idiopathic Sigmoid Megacolon: Report of a Case and Review of the Literature. Diseases of the Colon \& Rectum, 46, 833-835. https://doi.org/10.1007/s10350-004-6306-x

[3] Ribas, Y., Bargallo, J., Lamas, S. and Aguilar, F. (2013) Idiopathic Sigmoid Megacolon with Fecal Impaction and Giant Calcified Fecaloma. The American Surgeon, 792, E96-E97.

[4] Aiyappan, S.K., Ranga, U., Samraj, A., Rajan, S.C. and Veeraiyan, S. (2013) A Case of Fecaloma. Indian Journal of Surgery, 75, 323-324. https://doi.org/10.1007/s12262-012-0460-5

[5] Caiazzo, P., De martino, C., Del Vecchio, G., Di Lascio, P., Marasco, M., Laviani, F., et al. (2013) Megacolon for a Giant Fecaloma with Unlucky Outcome: Case Report and Review of the Literature. Annali Italiani di Chirurgia, 84, 319-322.

[6] Alvarez, C., Hernández, M.A. and Quintano, A. (2006) Clinical Challenges and Im- 
ages in GI: Image 2: Deep Venous Thrombosis Due to Idiopathic Megarectum and Giant Fecaloma. Gastroenterology, 131, 702-703.

https://doi.org/10.1053/j.gastro.2006.07.043

[7] Lohlun, J., Margolis, M., Gorecki, P. and Schein, M. (2000) Fecal Impaction Causing Megarectum-Producing Colorectal Catastrophes. A Report of Two Cases. Digestive Surgery, 17, 196-198. https://doi.org/10.1159/000018833

[8] Altomare, D.F., Rinaldi, M., Sallustio, P.L. and Armenise, N. (2009) Giant Fecaloma in an Adult with Severe anal Stricture Caused by Anal Imperforation Treated by Proctocolectomy and Ileostomy: Report of a Case. Diseases of the Colon \& Rectum, 52, 534-537. https://doi.org/10.1007/DCR.0b013e318199db36

Submit or recommend next manuscript to SCIRP and we will provide best service for you:

Accepting pre-submission inquiries through Email, Facebook, LinkedIn, Twitter, etc. A wide selection of journals (inclusive of 9 subjects, more than 200 journals)

Providing 24-hour high-quality service

User-friendly online submission system

Fair and swift peer-review system

Efficient typesetting and proofreading procedure

Display of the result of downloads and visits, as well as the number of cited articles

Maximum dissemination of your research work

Submit your manuscript at: http://papersubmission.scirp.org/

Or contact ojgas@scirp.org 